\title{
ATRIBUTOS FÍSICOS E PH DE UM FRAGMENTO DO RIO TAQUARI SOB A MINERAÇÃO DE BAUXITA NO PLANALTO DE POÇOS DE CALDAS - MG
}

\author{
D. A. BARROS, B. M. SILVA, R. A. SILVA, J. A. A. PEREIRA, L. A. C. BORGES, E. L. PEREIRA e G. O. NASCIMENTO \\ Universidade Federal de Lavras \\ rossiallan@gmail.com
}

Artigo submetido em abril/2013 e aceito em fevereiro/2014

DOI: $10.15628 /$ holos.2014.1378

\section{RESUMO}

O presente trabalho objetivou avaliar a qualidade física de um curso d'água localizado no Planalto de Poços de Caldas (MG) antes, durante e após a mineração de bauxita. Para tanto, foram analisados alguns parâmetros físicos que refletem a qualidade d'água do Rio Taquari, em diferentes períodos do processo de mineração as coletas duraram três meses em cada época: antes; durante; após, e dois anos depois da mineração; a primeira coleta foi em janeiro 2006 e a última em fevereiro de 2009. A coleta das amostras seguiu a normatização ABNT-NBR 9898 e as metodologias analíticas, procedimentos descritos pela APHA. Concluíram-se, através das análises efetuadas, que não foram verificadas diferenças significativas entre os valores dos parâmetros físicos de qualidade da água analisados para os pontos a montante e a jusante da área de interferência dos projetos minerários. Para os parâmetros $\mathrm{pH}$, cor, turbidez e sólidos sedimentáveis, não houve diferença significativa entre os períodos estudados, já para sólidos suspensos e sólidos totais ocorreu diferença significativa entre os períodos antes e depois da área lavrada e aqueles encontrados dois anos após o término da lavra. Também os resultados obtidos caracterizam a eficiência dos sistemas de controle ambiental utilizadas pela empresa. Nenhum dos valores encontrados para os parâmetros analisados superou os limites máximos permitidos pela legislação ambiental.

PALAVRAS-CHAVE: atividade minerária, águas superficiais, impacto ambiental.

\section{PHYSICAL ATTRIBUTES AND PH OF A FRACTION RIVER TAQUARI UNDER INFLUENCE OF BAUXITE MINING ON THE POÇOS DE CALDAS - MG}

\begin{abstract}
This study aimed to evaluate the physical quality of a watercourse located in Plateau of Poços de Caldas (MG) before, during and after bauxite mining. Therefore, we analyzed some physical parameters that reflect the water quality of the Rio Taquari, in three months before, during (April, July and September 2006), and after two years of mining. Sample collection followed the standardization ABNT NBR-9898 and the analytical methodologies, procedures described by APHA. It is concluded, through the analyzes, which were not significant differences between the values of the physical parameters of water quality for the points upstream and downstream of the
\end{abstract}

interference area of mining projects. Also the results obtained characterize the efficiency of environmental control systems used by the company. For the parameters $\mathrm{pH}$, color, turbidity and settle able solids, no significant difference between the studied periods, by other hand for suspended solids and total solids was significant difference between the periods before and after mining and those found during and two years after mining. None of the values for the parameters analyzed exceeded the maximum limits allowed by environmental legislation.

KEYWORDS: mining activity, surface waters quality, environmental impact. 


\section{INTRODUÇÃO}

A água ocupa um lugar específico entre os recursos naturais. É a substância mais abundante no planeta, embora sua disponibilidade não seja uniforme pela superfície do globo. De acordo com Bueno et al. (2005), o crescimento demográfico e o desenvolvimento socioeconômico são frequentemente acompanhados de aumentos na demanda por água, cuja quantidade e qualidade são de fundamental importância para a saúde e desenvolvimento de qualquer comunidade.

Goulart \& Callisto (2003) afirmam que o crescimento das cidades tem sido responsável pelo aumento da pressão das atividades antrópicas sobre os recursos naturais. O que se observa é uma forte pressão do sistema produtivo sobre os recursos naturais, visando matéria-prima utilizada na produção de bens de consumo. O desenvolvimento gera degradação, seja pela deposição de rejeitos e efluentes, seja pelo exaurimento dos recursos naturais que, muitas vezes, causa danos irreversíveis ao meio ambiente (RODGHER et al., 2005; OLIVEIRA et al., 2010).

Neste sentido, Mechi \& Sanches (2010), afirmaram que a atividade minerária pode causar severas alterações no regime hidrológico de uma região em função do seu consumo. De acordo com Romano et al. (2006), o setor minerário se utiliza de grandes quantidades de água, apresentando uma série de características particulares. A mineração abrange empreendimentos complexos que causam inúmeros impactos ambientais, ao mesmo tempo existem modernos e eficientes sistemas de controles ambientais, até pequenos extratores de areia, sem nenhum planejamento e controle ambiental e, muitas vezes com indulgências da comunidade local. São muitos os empreendimentos sem, ou com precário, controle ambiental, que comprometem diariamente os recursos naturais de nosso país (CASTRO et al., 2009). Porém, existem soluções para reduzir as perdas ambientais relacionadas com a água.

Considerações sobre as perspectivas de longo prazo no aproveitamento dos recursos e o equilíbrio entre alternativas de expansão de capacidade e gestão da demanda são atributos que vêm sendo associados a uma visão mais recente da gestão de recursos hídricos, conhecida como gestão integrada. Iniciativas voltadas ao controle de poluição na fonte, contrapostas à postura convencional de ampliar as capacidades estruturais de tratamento dos efeitos, constituem elementos de gestão integrados que cada vez mais se aplicam as bacias hidrográficas (SILVA \& PORTO, 2003).

O uso de índices de qualidade de água é uma tentativa que todo programa de monitoramento de águas superficiais prevê como forma de acompanhar, através de informações resumidas, a possível deterioração dos recursos hídricos ao longo da bacia hidrográfica ou ao longo do tempo (TOLEDO \& NICOLELLA, 2002; BLUME et al. 2010). Magalhães Jr. (2000) considera o monitoramento como um processo essencial a implementação da gestão das águas, determinados pela Lei $9433 / 97$ (BRASIL, 1997).

Entretanto, Bárbara et al. (2010) afirmam que é preciso maior atenção dos órgãos públicos quanto a avaliação da eficiência de suas ações gestoras, tornando mais assertivo o conhecimento acerca do comportamento da qualidade das águas superficiais, para que diferentes empreendimentos, sejam operados de maneira a não degradar ou mesmo tornar indisponível os recursos hídricos para outras atividades, respeitando, os princípios dos usos múltiplos da água. 
Complementando a Política Nacional de Recursos Hídricos, a Resolução CONAMA no 357, de 17 de março de 2005 e a Deliberação Normativa Conjunta COPAM/CERH-MG no 1 de 05 de maio de 2008, em nível federal e em Minas Gerais, respectivamente, classificam os corpos d'água de acordo com o uso ao qual a água se destina. Para as classes de corpos d'água, de acordo com estas normatizações, são definidos limites e, ou, condições mínimas de qualidade com base em parâmetros físicos e químicos (CONAMA, 2005; COPAM/CERH, 2008).

Para as avaliações de impactos ambientais (POWER et al., 2011) os parâmetros de pureza da água de interesse são o $\mathrm{pH}$ e a turbidez, necessários para atender aos critérios de qualidade da água, além da necessidade de monitorar os atributos em períodos maiores. A água é um componente vital e as interações que ocorrem no ambiente refletem diretamente na qualidade, quantidade e confiabilidade dos serviços ecossistêmicos. A complexidade destas interações é mal compreendida, daí a sua necessidade de monitoramento (MACE et al., 2012).

Deste modo, o presente trabalho objetivou avaliar a qualidade física de um curso d'água localizado no planalto de Poços de Caldas (MG) antes, durante e após atividades de lavra de bauxita, a montante e a jusante da área do empreendimento minerário, além de auxiliar nas tomadas de decisões para futuras instalações minerárias na região.

\section{MATERIAIS E MÉTODOS}

\subsection{Caracterização regional}

Localizada numa região de serras cujo substrato geológico é constituído por um maciço alcalino de forma aproximadamente circular, a região onde se situam as áreas do estudo é conhecida como planalto de Poços de Caldas. O planalto ocupa uma área aproximada de 6.558 $\mathrm{km}^{2}$, limitando-se a norte e leste com a Unidade Geomorfológica do Planalto de Varginha, a sul e sudeste com a depressão de Sapucaí e o planalto de Lindóia, e a oeste com a depressão Tietê, em Mogi Guaçu. Esta unidade constitui um compartimento topográfico elevado com altimetria variável entre $1.000 \mathrm{~m}$ e $1.300 \mathrm{~m}$, e pontos cotados a mais de $1.640 \mathrm{~m}$ de altitude. Esta área é abrangida por redes de drenagens pertencentes à bacia hidrográfica do Rio Paraná, sub-bacia do Rio Grande (GATTO et al.,1983).

O início da história fisiográfica da área de estudo dá-se durante o Cretáceo Superior, com o processo de intrusão alcalina, definindo inicialmente a formação de paisagens montanhosas, estendendo-se aos domínios vulcânicos de Itatiaia e Passa Quatro (MORAES \& JIMÉNEZ-RUEDA, 2008).

O clima é do tipo Cwb, subtropical de altitude, segundo a classificação de Köppen, mesotérmico com verões brandos e estiagem de inverno. A estação chuvosa estende-se de outubro a março, o índice pluviométrico anual médio é de $1.482 \mathrm{~mm}$. A temperatura média anual é de $19,9^{\circ} \mathrm{C}$ e a umidade relativa média anual de $79 \%$ (POÇOS DE CALDAS, 1992).

O planalto de Poços de Caldas encontra-se na região do domínio da Mata Atlântica (VELOSO et al., 1991), sendo as principais formações florestais classificadas como Floresta Estacional Semi decidual Alto-Montana (OLIVEIRA-FILHO, 2006; OLIVEIRA-FILHO et al., 2006). A região também apresenta fitofisionomias de campos de altitude e matas de galeria (GUIMARÃES et al., 2008). 


\subsection{Caracterização da área de estudo}

Para a coleta das amostras foi escolhida ao acaso uma jazida pertencente à Companhia Brasileira de Alumínio, a Mina Taquari (DNPM 16.443/35). A poligonal da Mina Taquari perfaz um montante de 532,63 ha de acordo com o Manifesto de Lavra no 3.003 de 26/06/1935.

A vegetação natural da área de estudo é constituída por um mosaico de formações vegetais, principalmente por fragmentos de florestas estacionais semideciduais, grandes áreas de campos altimontanos, pastagens e reflorestamentos de eucalipto. Destaca-se a aptidão da região para a pecuária, sendo grande parte do solo da região ocupado desordenadamente com a atividade. Para a realização do diagnóstico hídrico na Mina Taquari foi analisada a qualidade da água do Rio Taquari.

O processo de extração da bauxita na Mina Taquari ocorreu entre os meses de abril a setembro de 2006, período de estiagem na região. Após o encerramento das atividades de lavra, o sistema de drenagem provisório foi desativado e implantado o sistema de drenagem definitivo. Esse se baseia na técnica de tanques sequenciais de decantação consistindo na construção de tanques, com dimensões conhecidas, nos pontos de inflexão do terreno, com a finalidade de reter sólidos advindos da área minerada até a estabilização dos sólidos desagregados do terreno (BARROS et al., 2012).

Os tanques foram monitorados periodicamente de acordo com o tempo de estabilização da área, onde foram medidos e avaliados os percentuais relativos às suas saturações. Sempre que necessário, os tanques de contenção eram limpos ao atingir $50 \mathrm{~cm}$ de sua saída, e o material retirado depositado em área específica. Concomitantemente, iniciaram-se as atividades de reconformação topográfica e reabilitação da área, que se perdurou até o final do período chuvoso subsequente.

\subsection{Aparato experimental}

\subsubsection{Coleta, preservação e análise da água}

Os procedimentos de amostragem e preservação foram efetuados em conformidade com a norma ABNT (1987). Coletaram-se amostras da água para um ponto a montante e outro a jusante da área de interferência direta do empreendimento.

Os parâmetros avaliados neste estudo foram: $\mathrm{pH}$, cor (mgPtCo $\left.\mathrm{L}^{-1}\right)$, turbidez (NTU), sólidos suspensos $\left(\mathrm{mg} \mathrm{L}^{-1}\right)$, sólidos totais $\left(\mathrm{mg} \mathrm{L}^{-1}\right)$ e sólidos sedimentáveis $\left(\mathrm{mL} \mathrm{L}^{-1}\right)$. As análises físicoquímicas foram realizadas de acordo com procedimentos descritos no "Standard Methods for the Examination of Waterand Wastewater (APHA, 2005). Para pH, utilizou o método potenciométrico com medidor de $\mathrm{pH}$ e leitura direta. A cor foi avaliada por comparação com soluções conhecidas de platina-cobalto. A turbidez foi feita por leitura direta em espectrofotômetro, avaliando a quantidade de luz refletida pelas partículas em suspensão. A avaliação de sólidos foi feita por gravimetria.

Para viabilizar as análises propostas para determinação dos impactos da atividade minerária sobre o curso d'água local, o período de amostragem foi dividido em quatro épocas. A primeira abrangendo o período anterior ao início das atividades de lavra (antes da mineração janeiro a março de 2006), o segundo abrangendo três meses de amostragens durante o período 
de lavra (durante a mineração - abril, julho e setembro de 2006), outro compreendendo os três meses subsequentes ao término das atividades minerárias (após a mineração - outubro, novembro e dezembro de 2006) e finalmente o período compreendendo mais três meses de coleta, aproximadamente dois anos após o fechamento da mina (após a mineração - outubro e dezembro de 2008 e fevereiro de 2009).

\subsubsection{Procedimento estatístico}

Cada parâmetro de qualidade da água avaliado foi submetido à ANOVA, utilizando o delineamento inteiramente casualizado, em esquema fatorial duplo $2 \times 4$, sendo as fontes de variação os dois pontos monitorados (montante e a jusante) e os 4 períodos avaliados, considerando cada mês de cada período uma repetição, visando detectar as possíveis diferenças entre os valores obtidos a montante e a jusante para os parâmetros analisados, e posteriormente as diferenças entre as épocas ou períodos considerados. O teste de médias Skott-Knott a $5 \%$ de probabilidade foi aplicado para separar as médias quando pertinente.

Utilizaram-se os limites máximos permitidos pela legislação vigente para confrontar com os valores médios de cada parâmetro nos períodos avaliados, verificando sua adequação a montante e a jusante da área de interferência do empreendimento minerário.

\section{RESULTADOS E DISCUSSÃO}

Conforme caracterizado na Figura 1, os valores de pH e sólidos suspensos, obtidos a partir das coletas realizadas para os pontos a montante e a jusante da área de influência do empreendimento minerário, se encontraram dentro dos limites máximos permitidos (LMP) estipulados pela legislação vigente. 

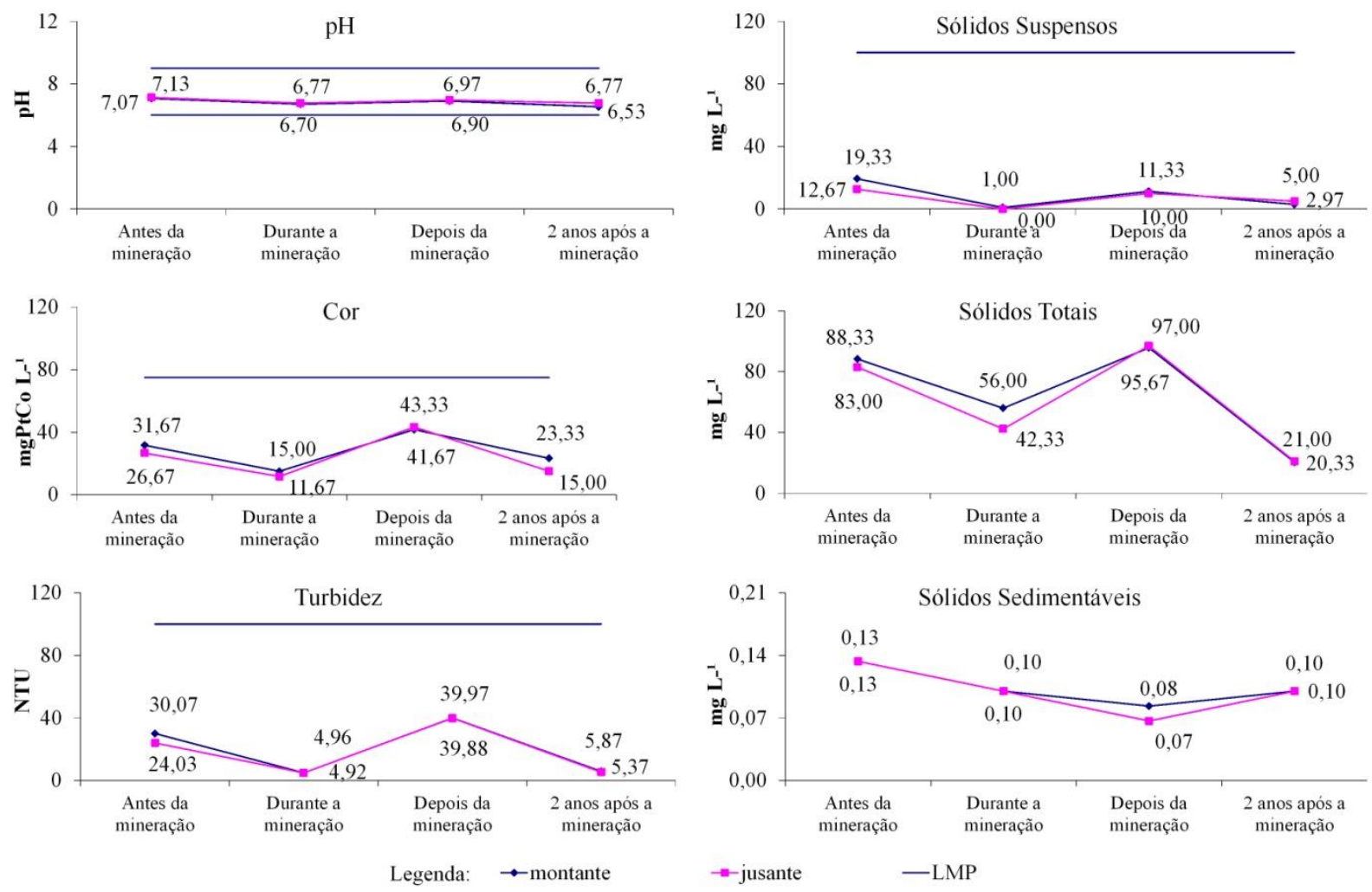

Figura 1. Evolução dos valores médios dos parâmetros considerados, ao longo dos períodos avaliados, para os pontos a montante e a jusante da área de intervenção minerária, no Rio Taquari.

Também verificando valores do parâmetro cor obtidos durante os períodos estudados, foi possível inferir que nenhum deles ultrapassaram $75,00 \mathrm{mgPtCo}^{-1}$, indicando conformidade com a legislação ambiental vigente. O comportamento da turbidez, foi semelhante, entretanto ocorreram oscilações ao longo de todo período analisado. Na realidade, os valores de turbidez estiveram, em média, 80\% menores que o LMP (FIGURA 1).

Conforme os resultados obtidos, referentes aos parâmetros sólidos totais e sólidos sedimentáveis, respectivamente, pôde-se observar também que não houveram diferenças entre os pontos para cada período. Para este parâmetro, a legislação ambiental vigente não infere valores máximos permitidos. Deste modo, todos os valores encontrados estão de acordo com àqueles esperados, uma vez que os demais parâmetros analisados apresentaram comportamentos similares. Fravet \& Cruz (2007) observaram teores de 41 a $183 \mathrm{mg} \mathrm{L}^{-1}$ para sólidos totais ao analisar amostras de águas utilizadas em irrigação de hortaliças por 10 produtores rurais em Botucatu-SP, e esses valores foram considerados não alarmantes, e possuem amplitude maior que os observados no presente trabalho.

Por meio da ANOVA realizada, verificou-se não haver interação entre os fatores período e ponto de amostragem (TABELA 1), em função do $p$-valor apresentado para cada parâmetro. Assim, o efeito de cada fator foi analisado separadamente. 
Tabela 1. Síntese da ANOVA, para cada parâmetro de qualdiade de água analisado, mostrando o P-valor para cada fonte de variação da área de intervenção minerária, no Rio Taquari.

\begin{tabular}{lcccccc}
\hline \multirow{2}{*}{ Fontes de Variação } & pH & Cor & Turbidez & $\begin{array}{c}\text { Sólidos } \\
\text { Suspensos }\end{array}$ & $\begin{array}{c}\text { Sólidos } \\
\text { Totais }\end{array}$ & $\begin{array}{c}\text { Sólidos } \\
\text { Sedimentáveis }\end{array}$ \\
\cline { 2 - 7 } & 0,07 & 0,26 & 0,15 & 0,01 & $<0,01$ & 0,19 \\
Período & 0,37 & 0,72 & 0,89 & 0,59 & 0,76 & 0,82 \\
Ponto & 0,95 & 0,98 & 0,99 & 0,81 & 0,97 & 0,98 \\
Interação Período x Ponto & 0,99 &
\end{tabular}

Obs.: cor (mgPtCo $\left.\mathrm{L}^{-1}\right)$, turbidez (NTU), sólidos suspensos $\left(\mathrm{mg} \mathrm{L}^{-1}\right)$, sólidos totais $\left(\mathrm{mg} \mathrm{L}^{-1}\right)$ e sólidos sedimentáveis $\left(\mathrm{mL} \mathrm{L}^{-1}\right)$.

Analisando o efeito do ponto de amostragem, pode-se observar que para todos os parâmetros avaliados não houve diferença significativa entre os valores encontrados a montante e a jusante da área de interferênciada da atividade minerária (TABELA 2).

Tabela 2. Efeito do ponto de amostragem sobre os parâmetros físico-químicos de qualidade da água superficial da área de intervenção minerária, no Rio Taquari.

\begin{tabular}{lcccccc}
\hline \multicolumn{1}{c}{ Ponto } & pH & Cor & Turbidez & $\begin{array}{c}\text { Sólidos } \\
\text { suspensos }\end{array}$ & $\begin{array}{c}\text { Sólidos } \\
\text { Totais }\end{array}$ & $\begin{array}{c}\text { Sólidos } \\
\text { Sedimentáveis }\end{array}$ \\
\hline $\begin{array}{l}\text { Montante } \\
\text { Jusante }\end{array}$ & $6,80 \mathrm{a}$ & $27,92 \mathrm{a}$ & $20,22 \mathrm{a}$ & $8,66 \mathrm{a}$ & $65,08 \mathrm{a}$ & $0,10 \mathrm{a}$ \\
& $6,91 \mathrm{a}$ & $24,17 \mathrm{a}$ & $18,55 \mathrm{a}$ & $6,92 \mathrm{a}$ & $60,83 \mathrm{a}$ & $0,10 \mathrm{a}$ \\
\hline
\end{tabular}

Médias seguidas de mesma letra na coluna são estatisticamente iguais pelo teste de Scott-Knott a 5\% de probabilidade. Obs.: cor (mgPtCo $\left.\mathrm{L}^{-1}\right)$, turbidez (NTU), sólidos suspensos (mg L $\left.\mathrm{L}^{-1}\right)$, sólidos totais (mg L $\mathrm{L}^{-1}$ ) e sólidos sedimentáveis $\left(\mathrm{mL} \mathrm{L}^{-1}\right)$.

No entanto, houve variação temporal entre as amostragens (Tabela 3). Para os parâmetros $\mathrm{pH}$, cor, turbidez e sólidos sedimentáveis, não houve diferença significativa entre os períodos estudados. Uma vez que o pH da água é controlado pelo equilíbrio na concentração de compostos dissolvidos (OLIVEIRA, 1989), pode-se observar que não houve alterações significativas dos compostos presentes nos locais e períodos avaliados. Entretanto, para os parâmetros sólidos suspensos e sólidos totais ocorreu diferença significativa ao nível de $5 \%$ entre os períodos anteriores e posteriores da mineração com aqueles encontrados durante e dois anos após a mineração. Ainda é importante ressaltar que nenhum deles superou os limites máximos permitidos pela legislação ambiental correlata e ainda foram, em média, maiores que aqueles encontrados durante e dois anos após o término das atividades de lavra.

Tabela 3. Efeito do período de amostragem sobre os parametros físico-químicos de qualidade da água superficial da área de intervenção minerária, no Rio Taquari.

\begin{tabular}{cccccccc}
\hline Período & $\begin{array}{c}\text { Precipitação } \\
\text { do período }\left(^{*}\right)\end{array}$ & $\mathbf{p H}$ & Cor & Turbidez & $\begin{array}{c}\text { Sólidos } \\
\text { suspensos }\end{array}$ & $\begin{array}{c}\text { Sólidos } \\
\text { Totais }\end{array}$ & $\begin{array}{c}\text { Sólidos } \\
\text { Sedimentáveis }\end{array}$ \\
\hline $\begin{array}{c}\text { Antes da } \\
\text { mineração }\end{array}$ & 838,00 & $7,10 \mathrm{a}$ & $29,17 \mathrm{a}$ & $27,05 \mathrm{a}$ & $16,00 \mathrm{a}$ & $85,67 \mathrm{a}$ & $0,13 \mathrm{a}$ \\
\hline $\begin{array}{c}\text { Durante } \mathrm{a} \\
\text { mineração }\end{array}$ & 165,00 & $6,73 \mathrm{a}$ & $13,33 \mathrm{a}$ & $4,94 \mathrm{a}$ & $0,50 \mathrm{~b}$ & $49,17 \mathrm{~b}$ & $0,10 \mathrm{a}$ \\
\hline $\begin{array}{c}\text { Depois da } \\
\text { mineração }\end{array}$ & 768,00 & $6,93 \mathrm{a}$ & $42,50 \mathrm{a}$ & $39,93 \mathrm{a}$ & $10,67 \mathrm{a}$ & $96,33 \mathrm{a}$ & $0,08 \mathrm{a}$ \\
\hline $\begin{array}{c}\text { Dois anos depois } \\
\text { da mineração }\end{array}$ & 806,00 & $6,65 \mathrm{a}$ & $19,17 \mathrm{a}$ & $5,62 \mathrm{a}$ & $3,98 \mathrm{~b}$ & $20,67 \mathrm{~b}$ & $0,10 \mathrm{a}$ \\
\hline
\end{tabular}

Médias seguidas de mesma letra na coluna são estatisticamente iguais pelo teste de Scott-Knotta 5\% de probabilidade. $\left({ }^{*}\right)$ Precipitação acumulada do período, calculada através do somatório da precipitação mensal de cada mês considerado. Obs.: cor (mgPtCo $\left.\mathrm{L}^{-1}\right)$, turbidez (NTU), sólidos suspensos $\left(\mathrm{mg} \mathrm{L}^{-1}\right)$, sólidos totais (mg $\left.\mathrm{L}^{-1}\right)$ e sólidos sedimentáveis $\left(\mathrm{mL} \mathrm{L}^{-1}\right)$. 
Avaliando os dados obtidos durante o período de mineração pôde-se observar baixos valores de cor, turbidez e sólidos suspensos e sedimentáveis, caracterizando uma adequada qualidade física da água, confirmando ausência de despejo de rejeitos do processo de lavra ou transporte de sedimentos por escoamento superficial. Deduz-se que o motivo possa ser decorrente de processos naturais, uma vez que, caso fosse proporcionado pela mineração observar-se-ia um aumento exagerado nos valores de sólidos totais, ao contrário dos baixos valores encontrados.

Chaves \& Santos (2009); Vanzela et al. (2010) estudando a influência do uso do solo na qualidade da água dos cursos hídricos próximos as áreas de ocupação, encontraram resultados que complementam este trabalho, ratificando que o uso e ocupação do solo (recuperação ambiental), normalmente, mitigam os impactos ambientais negativos, conservando a qualidade dos cursos d'água.

Correlacionando as precipitações dos períodos com a qualidade física da água, sugere-se que as oscilações nos valores dos parâmetros para cada período, tiveram forte influência da precipitação acumulada. Na realidade observa-se que durante a mineração ocorreram às menores quantidades de chuva, culminando nos menores valores para todos os parâmetros, excetuando pH e sólidos totais. Os mesmos resultados não foram constatados por Lucas et al. (2010) que observaram modificações apenas nos parâmetro químico fósforo e condutividade elétrica em função da precipitação. Pereira \& Mendonça (2005) verificaram que o efeito de diluição das chuvas atuou no sentido de diminuir as concentrações de sólidos dissolvidos, de fósforo total, de ferro solúvel e de ferro total.

Analisando os valores obtidos nas coletas realizadas após a atividade de mineração, percebe-se uma continuidade na tendência dos valores de todos os parâmetros analisados, permitindo inferir que a qualidade física da água, mesmo após o término da atividade mineradora, foi mantida.

Nos trabalhos conduzidos por Chaves \& Santos (2009) observou-se que mesmo com a ocupação e uso do solo e a fragmentação da paisagem não se verificou modificações na qualidade física, concluindo que, como a zona ripária se manteve relativamente íntegra no período estudado, ela amenizou eventuais impactos na qualidade da água na bacia, o mesmo que ocorreu neste trabalho devido aos sistemas de drenagem instalados ao redor das frentes de lavra.

O período dois anos após a lavra também apresentou, da mesma forma, os baixos valores, porém altos valores de precipitação. Esses resultados não sugerem influência das chuvas, porém da estabilidade da área em função da eficácia do sistema de recuperação ambiental da área. Provavelmente, esse comportamento também teve sua origem na eficiência dos sistemas de controle ambiental implantados.

Nos estudos realizados por Vanzela et al. (2010), as áreas ocupadas por matas e pastagens (em menor intensidade) favoreceram o aumento da vazão específica e a melhoria de alguns atributos de qualidade de água. As áreas habitadas, agricultáveis e as matas degradadas reduziram, de modo geral, a vazão específica e a qualidade da água.

Neste trabalho não foram observadas modificações da vazão em função da ocupação da atividade minerária, isso porque não houve descarte ou escoamento de nenhum material para o curso d'água local e também provavelmente pelo bom estado de conservação da vegetação ciliar. 


\section{CONCLUSÕES}

Não foram verificadas diferenças significativas entre os valores dos parâmetros físicos de qualidade da água analisados, durante cada período considerado, para os pontos a montante e a jusante da área de interferência dos projetos minerários.

De acordo com os resultados obtidos, foi possível inferir que houve eficiência dos sistemas de controle ambiental utilizados para a mitigação dos impactos sobre o corpo d'água para os parâmetros analisados.

Para os parâmetros $\mathrm{pH}$, cor, turbidez e sólidos sedimentáveis, não houve diferença significativa entre os períodos estudados.

Para os parâmetros sólidos suspensos e sólidos totais ocorreu diferença significativa entre os períodos anteriores e posteriores a mineração, em relação aos valores encontrados durante e dois anos após a mineração.

Nenhum dos valores encontrados para os parâmetros analisados superou os limites máximos permitidos pela legislação ambiental.

A precipitação ocorrida em alguns períodos pode ter influenciado os resultados da qualidade física da água.

\section{REFERÊNCIAS BIBLIOGRÁFICAS}

1. ABNT. Associação Brasileira de Normas Técnicas. Fórum Nacional de Normatização NBR-9898 - Preservação e técnicas de amostragem de efluentes líquidos e corpos receptores. 1987.

2. APHA. American Public Health Association. Standard methods for the examination of water and wastewater. Washington, 2005.

3. BÁRBARA, V. F.; CUNHA, A. C.; RODRIGUES, A. S. L.; SIQUEIRA, E. Q. Monitoramento sazonal da qualidade da água do rio Araguari/AP. Revista Biociências, Taubaté, v. 16, n. 1, p. 57-72, 2010.

4. BARROS, D. A.; GUIMARÃES, J. C. C.; PEREIRA, J. A. A.; BORGES, L. A. C.; SILVA, R. A.; PEREIRA, A. A. S. Characterization of the bauxite mining of the Poços de Caldas alkaline massif and its socio-environmental impacts. Revista Escola de Minas, Ouro Preto, v. 65, n. 1, p. 127-133, jan./mar., 2012.

5. BLUME, K. K.; MACEDO, J.C.; MENEGUZZI, A.; SILVA, L. B.; QUEVEDO, D. M.; RODRIGUES, M. A. S. Water quality assessment of the Sinos River, Southern Brazil. Brazilian Journal of Biology, São Carlos, v. 70, n. 4, p. 1185-1193, 2010.

6. BRASIL. Lei Federal n. 9.433, de 08 de janeiro de 1997. Dispõe sobre a PNRH e Sistema Nacional de Gerenciamento de Recursos Hídricos. Brasília, DF. Disponível em: <http://www.planalto.gov.br/ccivil_03/leis/L9433.htm>. Acesso em: 15 jun. 2010.

7. BUENO, L. F.; GALBIATTI, J. A.; BORGES, M. J. Monitoramento de variáveis de qualidade da água do Horto Ouro Verde - Conchal - SP. Engenharia Agrícola, Jaboticabal, v. 25, n. 3, p. 742748, 2005.

8. CASTRO, L. M.; BARROS, D. A.; PEREIRA, A. A. S. Monitoramento de Águas Superficiais em Área 
de Explotação de Bauxita, no Planalto de Poços de Caldas, Minas Gerais. Revista Científica Aprender, 3a edição, 2009.

9. CHAVES, H M. L.; SANTOS, L. B. Ocupação do solo, fragmentação da paisagem e qualidade da água em uma pequena bacia hidrográfica. Revista Brasileira de Engenharia Agrícola e Ambiental, Campina Grande, v. 13, Suplemento, p. 922-930, 2009.

10. CONAMA. Resolução CONAMA no 357, de 17 de março de 2005. Dispõe sobre a classificação dos corpos d'água e define diretrizes ambientais para seu enquadramento, bem como estabelece condições e padrões de lançamento de efluentes, e dá outras providencias. Publicada no Diário Oficial da União de 18/03/05. Seção 1. Páginas 58 a 63. Disponível em <http://www.mma.gov.br/port/conama/res/res357/res35705.html>. Acesso em 21/07/2010.

11. COPAM/CERH. Deliberação Normativa Conjunta COPAM/CERH-MG no 1 de 05 de maio de 2008. Dispõe sobre a classificação dos corpos de água de acordo com o uso ao qual a água se destina, e dá outras providencias. Publicada no Diário do Executivo do estado de Minas Gerais de 13/05/2008. Disponível em: <http://www.siam.mg.gov.br/sla/download.pdf?idNorma= 8151>. Acesso em 18/04/2010.

12. FRAVET, A.M.M.F.; CRUZ, R.L. Qualidade da água utilizada para irrigação de hortaliças na região de Botucatu-SP. Irriga, v.12, n.2, p. 144-155, 2007.

13. GATTO, L. C. S.; RAMOS, V. L. S.; NUNES, B. T. A.; MAMED, L.; GÓES, M. H. B.; MAURO, C. A.; ALVARENGA, S. M.; FRANCO, E. M. S.; QUIRICO, A. F.; NEVES, L. B. Capítulo II - Geomorfologia: Geologia, Geomorfologia, Pedologia, Vegetação e Uso Potencial da Terra. In: Projeto Radambrasil, SF23 - Rio de Janeiro e SF24 - Vitória. Rio de Janeiro, 1983. 351 p.

14. GOULART, M.; CALLISTO, M. Bioindicadores de qualidade de água como ferramenta em estudos de impacto ambiental. Revista da FAPAM, v. 2, n. 1, 2003.

15. GUIMARÃES, J. C. C.; VAN DEN BERG, E.; CASTRO, G. C.; MACHADO, E. L. M.; OLIVEIRA-FILHO, A. T. Dinâmica do componente arbustivo-arbóreo de uma floresta de galeria aluvial no planalto de Poços de Caldas, MG, Brasil. Revista Brasileira de Botânica, São Paulo, v. 31, n. 4, p. 621632, out./dez., 2008.

16. LUCAS, A. A. T.; FOLEGATTI, M. V.; DUARTE, S. N. Qualidade da água em uma microbacia hidrográfica do Rio Piracicaba, SP. Revista Brasileira de Engenharia Agrícola e Ambiental, Campina Grande, v. 14, n. 9, p. 937-943, 2010.

17. MACE, G. M.; NORRIS, K.; FITTER, A. H. Biodiversity and ecosystem services: a multilayered relationship. Trends in Ecology and Evolution, v. 27, n. 1, pp. 19-26, jan, 2012.

18. MAGALHÃES JR, A. P. A. Situação do monitoramento de águas do Brasil - instituições e iniciativas. Revista Brasileira de Recursos Hídricos, Porto Alegre, v. 5, n. 3, p. 113-135, 2000.

19. MECHI, A.; SANCHES, D. L. Impactos ambientais da mineração no Estado de São Paulo. Estudos Avançados, São Paulo, v. 24, n. 68, p. 209-220, 2010.

20. MORAES, F. T.; JIMÉNEZ-RUEDA, J. R. Fisiografia da região do planalto de Poços de Caldas, MG/SP. Revista Brasileira de Geociências, São Paulo, v. 38, n. 1, p. 196-208, 2008.

21. OLIVEIRA, C. N.; CAMPOS, V. P.; MEDEIROS, Y. D. P. Avaliação e identificação de parâmetros importantes para a qualidade de corpos d'água no semiárido baiano. Estudo de caso: bacia hidrográfica do Rio Salitre. Química Nova, v. 33, n. 5, p. 1059-1066, 2010.

22. OLIVEIRA, F. A. Produção e qualidade da água em bacias hidrográficas contendo diferentes HOLOS, Ano 30, Vol. 4 
coberturas vegetais na região de agudos, São Paulo. 1989. 96 p. Dissertação (Mestrado em Hidrologia Florestal) - Escola Superior de Agricultura "Luiz de Queiroz", Universidade de São Paulo, Piracicaba, 1989.

23. OLIVEIRA-FILHO, A. T. Catálogo das Árvores Nativas de Minas Gerais - Mapeamento e Inventário da Flora Nativa e dos Reflorestamentos de Minas Gerais. Lavras: UFLA, 2006. 423 p.

24. OLIVEIRA-FILHO, A. T., JARENKOW, J. A., RODAL, M. J. N. Floristic relationships of seasonally dry forests of eastern South America based on tree species distribution patterns. In: PENNINGTON, R. T., RATTER, J. A., LEWIS, G. P. (eds.) Neotropical savannas and dry forests: Plant diversity, biogeography and conservation. Boca Raton, EUA: CRC Press, p. 151-184, 2006.

25. PEREIRA, A.A, MENDONÇA, A.S.F. Aspectos Qualitativos de Águas de Lagoas Costeiras e seus Fatores Influentes - Estudo de Caso: Lagoa MÃE-BÁ, Espírito Santo. Revista Brasileira de Recursos Hídricos, v. 11, n. 1, p. 63-77, 2005.

26. POÇOS DE CALDAS. PREFEITURA MUNICIPAL DE POÇOS DE CALDAS - PMPC. Plano Diretor Municipal. Poços de Caldas, MG: Prefeitura Municipal de Poços de Caldas, 1992. Disponível em: <http://www.pocosdecaldas.mg.gov.br>. Acesso em: 01 fev. 2012.

27. POWER, G.; GRÄFE, M.; KLAUBER, C.; Bauxite residue issues: I. Current management, disposal and storage practices. Hydrometallurgy, v. 108, n. 1-2, pp. 33-45, 2011.

28. RODGHER, S.; ESPÍNDOLA, E. L. G.; ROCHA, O.; FRACÁCIO, R.; PEREIRA, R. H. G.; RODRIGUES, M. H. S. Limnological and ecotoxicological studies in the cascade of reservoirs in the Tietê River (São Paulo, Brazil). Brazilian Journal Biology, v. 65, n. 4, p. 697-710, 2005.

29. ROMANO, E.; ROMANO, P. A.; FEITOSA. V. M. N. Gestão descentralizada e participativa dos recursos hídricos e a mineração: riscos e oportunidades. In: DOMINGUES, A. F.; BÓSON, P. H. G.; ALÍPAZ, S. A. Gestão dos recursos hídricos e a mineração. Brasília: ANA, 2006. p. 53-67.

30. SILVA, R. T. \& PORTO, M. F. A. Gestão urbana e gestão das águas: caminhos da integração Estudos Avançados. v. 17, n. 47, pp. 129-145. 2003.

31. TOLEDO, L. G.; NICOLELLA, G. Índice de qualidade de água em microbacia sob uso agrícola e urbano. Scientia Agrícola, Piracicaba, v. 59, n. 1, p. 181-186, 2002.

32. VANZELA, L. S.; HERNANDEZ, F. B. T.; FRANCO, R. A. M. Influência do uso e ocupação do solo nos recursos hídricos do Córrego Três Barras, Marinópolis. Revista Brasileira de Engenharia Agrícola e Ambiental. Campina Grande, v. 14, n. 1, p. 55-64, 2010.

33. VELOSO, H. P.; RANGEL FILHO, A. L. R.; LIMA, J. C. A. Classificação da vegetação brasileira adaptada a um sistema universal. Rio de Janeiro: IBGE, 1991. $88 \mathrm{p}$. 